\title{
Strategies for the Control of Coronavirus Disease (COVID 19) and Production of Stigma: Case of the Health District of Cocody-Bingerville in Cote D'Ivoire
}

\author{
Kambe Kambe Yves ${ }^{1}$, Ouattara Kalilou ${ }^{1}$, Hyda Jules ${ }^{2}$, Ouattara Amadou ${ }^{3}$ \\ ${ }^{1}$ Institute of Ethno-Sociology, Felix Houphouet Boigny University, Abidjan, Ivory Coast \\ ${ }^{2}$ National Blood Transfusion Center (NBTC), Ivory Coast \\ ${ }^{3}$ Pasteur Institute, Abidjan, Ivory Coast
}

Email address:

kambekves@yahoo.fr (K. K. Yves), ouattara_kalilou@yahoo.fr(O. Kalilou),hyda_j@yahoo.fr (H. Jules), ouatt78@yahoo.fr (O.Amadou)

To cite this article:

Kambe Kambe Yves, Ouattara Kalilou, Hyda Jules, Ouattara Amadou. Strategies for the Control of Coronavirus Disease (COVID 19) and Production of Stigma: Case of the Health District of Cocody-Bingerville in Cote D'Ivoire. International Journal of Infectious Diseases and Therapy. Vol. 6, No. 1, 2021, pp. 27-36. doi: 10.11648/j.ijidt.20210601.14

Received: December 14, 2020; Accepted: January 28, 2021; Published: February 23, 2021

\begin{abstract}
In the history of the various (re) emerging diseases, it has been noted that the stigma of people tested positive has been produced. These negative attitudes and behaviors have been observed on all continents. Thus, the objective of this study was to establish a link between health response plans for coronavirus disease (covid 19) and the production of stigma. Indeed, declared a "public health emergency of international concern (USPPI)" by the World Health Organization (2020), covid-19 is characterized by a strong and rapid spread. To reduce this diffusion, health response plans have been implemented and supported by extensive communication campaign. However, in Côte d'Ivoire, the analysis of data from a literature review, interviews with 310 people using an electronic questionnaire and an interview guide with four health officials, showed that the different strategies adopted are fueling and reinforcing the fear of this disease and the death that can result from it. As a result, they have led to attitudes that reject and stigmatize positive people and their loved ones. As a result, like previous emerging diseases, covid-19 has achieved the same result in populations. Thus, we consider that the different strategies for responding to emerging diseases contribute in large part to the production of this social reaction, which is a legitimate response based on the survival instinct buried in each individual.
\end{abstract}

Keywords: Emerging Disease, COVID 19, Health Response, Strategies, Stigma

\section{Introduction}

C. Nicolle [1] wrote: "so there will be new diseases, it is a fatal fact. Another fact, as fatal, is that we will never know how to track them from the start. When we have a sense of these diseases, they will all be formed, adults, one might say".

This recall of the author has been observed in recent decades with the emergence of emerging diseases such as HIV/AIDS (in 1981), Ebola disease in West Africa (in 2013) and Central Africa (from 1976 to 2020) ${ }^{1}$ and coronavirus

\footnotetext{
1 Since early May 2020, the Democratic Republic of Congo has faced its ninth Ebola outbreak since 1976. Other countries such as Sudan, Uganda, Gabon and Congo have been affected during this period. However, this time interval was marked by years without ebola.
}

disease (covid 19) reported for the first time was in Wuhan, China, on December 31, 2019.

The last one (covid 19) quickly spread to several other countries. Outbreaks and clusters of the disease have since been observed in Asia, Europe, Australia, the Americas and Africa)"[2].

The rapid spread of the latter disease led the World Health Organization (WHO) to declare a "public health emergency of international concern (USPPI)"[3]. In fact, in the space of five months (January to May 19, 2020), 4,836,329 people were tested positive and 19,213 died [4] ${ }^{2}$.

To reduce its spread, health responses have been implemented. Thus, the different countries have adopted a

2 This source was consulted on May 19, 2020 at 02: $32 \mathrm{~min}$ am. 
global approach adapted to their circumstances.

In Côte d'Ivoire, the government has put in place a strategy to curb the spread of this disease. This strategy covers a range of barrier measures (border closures, containment, quarantine, emergency, curfew, social or physical separation and hygiene) supported by a broad communication campaign.

All these actions, which have undoubtedly helped to curb the spread of the pandemic, have been able to generate social attitudes and behaviors. UNAIDS [5] warned "we are all going through a difficult time. [We ask] to show kindness and not to stigmatize or discriminate. People affected by Covid 19 are an integral part of the solution and should receive our support".

This UNAIDS inquiry is sounding the alarm that, given the contagious and deadly nature of Covid 19, there is a risk of a community withdrawal that is favorable to the production of stigmatization against people tested positive or those who reside in the neighborhoods identified as the most affected. Hence the question, what are the psychosocial consequences of strategies to combat covid 19? To answer this question is to demonstrate the inevitability of the stigma produced by the strategies against covid-19. Therefore, we state that stigma is prevalent in the strategies to combat covid-19.

\section{Methodology}

\subsection{Type and Duration of the Study}

The study is transversal. It took place from May to October 2020. The data were collected in August 2020.

\subsection{Study Framework}

The study was conducted in the health district of CocodyBingerville. This district recorded the most cases during the pandemic.

\subsection{Type and Duration of the Study}

The study is transversal. It took place from May to October 2020. The data were collected in August 2020.

\subsection{Target Population}

The study covered:

1) Population living in the Cocody-Bingerville Health District,

2) Health officials: Rapid Response Team (RRT), Management Cell (National Institute of Public Hygiene, Infectious and Tropical Diseases Department of the Treichville University Hospital Center, Ministry of Health and Public Hygiene),

3) Documents: films, reports, images and decision of the Ivorian Government on the pandemic.

\subsection{Sampling}

\subsubsection{Population}

As part of our study, we built a representative sample. We calculated the sample size using the following formula: $n=t^{2}$ $\times p \times(1-p) / m^{2}$, where

1) n: Minimum sample size for achieving meaningful results for an event and a set level of risk

2) t: Confidence level (the typical $95 \%$ confidence level will be 1.96)

$3) \mathrm{p}$ : estimated proportion of the population with the characteristic

4) m: Margin of error (typically 5\%).

So for our object with a $50 \%$ probability of achievement, taking a $95 \%$ confidence level and a $5 \%$ margin of error, the sample size was

$\mathrm{n}=1,962 \times 0.7 \times 0.3 / 0.052=322.69$ or 323 individuals.

According to the 2014 General Population and Habitat Census, the health district of Cocody-Bingerville had 538,374 of whom 447,055 lived in Cocody, $83 \%$ and 91,319 in Bingerville, $17 \%$ [6].

Therefore, the sample is divided as follows:

Table 1. Sample distribution by survey site.

\begin{tabular}{lll}
\hline Site & Proportion & Sampling \\
\hline Cocody & 83 & 268 \\
Bingerville & 17 & 55 \\
Total & 100 & 323 \\
\hline
\end{tabular}

\subsubsection{Health Managers}

1) EIR: 1 coordinator

2) Management Cell: 1 INHP, 1 SMIT, 1 MSHP

\subsubsection{Documentation}

1) RTI 1 Report: testimonials, images

2) Government decisions

\subsection{Tools}

We used three data collection tools: a questionnaire, interview guide and observation grid. The first was used to collect quantitative data. It was addressed to the people.

The second was used to collect qualitative data such as perceptions and speeches. It was intended for the health authorities.

The latter was developed to record documentary data (films, reports and images).

\subsection{Data Collection Technique}

The health situation of Covid 19 did not allow us to administer the questionnaire directly to the respondents.

To get around this difficulty, we imported our questionnaire into google forms. This electronic version has been sent to all our email contacts. All those living in the target communities (Cocody and Bingerville) were invited not only to complete the electronic questionnaire, but also to transfer it to their various contacts living in the study areas concerned. On the other hand, all those who do not live in the two communes mentioned above are invited to transfer it to their contacts living in the study areas.

With the snowball effect, we were able to fill in our data 
collection tool.

\subsection{Method of Analysis}

In this study, we have chosen the dialectical method as a method of analysis because it takes into account both historical, comparative, systemic, structuro-functionalist, constructivist and statistical approaches.

In fact, according to P. Rongere [7], the dialectical method applies to grasp the relationships of dynamic contradictions of social reality. It can be an attempt to develop between a dialectical explanation (by history) and a synchronous explanation (by structure). This law of contradiction complements the law of change in that everything is called to change, but gives the opposite element. It is the struggle of the opposite to give a new thing. This law is reflected in the daily life of every society or man. Indeed, the human experience is made of the coexistence of the 'yes' and the 'no' in terms of positivity and negativity. In the case of our study, there is a contradiction between traditional and modern medicine about methods. Traditional medicine chooses the use of the pear almost exclusively while medicine has many reservations about its use.

\subsection{Theories}

Stigma is a process that results from three concomitant dimensions: an indication, meaning and direction for the action. Indication is the identification of the subject (social labeling), while meaning is the expression of a depreciation against a subpoena. Finally, stigma involves the formulation of a guideline to trigger and legitimize attitudes and behaviors towards the stigmatized community.

Dealing with this issue is thus revisiting the theories of labeling, community withdrawal and social rejection.

\subsubsection{Labeling Theory}

Social labeling is an inherent public health risk: the nature of the institution's actions and a context of scarcity of resources (human and financial) are among the underlying conditions.

Public health, faced with the imperatives of utility, must "maximize the effectiveness of prevention, protection and health promotion interventions, and [avoid] wasting resources on large sections of a population not concerned by a given public health issue" [8].

To achieve this, public health draws a health profile of the population and divides it into "target groups" based on behaviors, living conditions or characteristics considered "at risk".

However, as effective as it may be, such an approach can also entail social costs, such as stigmatizing certain groups of individuals targeted for intervention.

\subsubsection{Community Fallback Theory}

One of the responses to individuals or groups marked or labeled at risk is community or social withdrawal.

\subsubsection{Theory of Social Rejection}

The labeling process results in social rejection of individuals or groups marked or labeled at risk. It is a process of victimization and rejection based on a duty of obviousness.

\section{Results}

\subsection{Identification of Respondents}

Initially, 363 people should be interviewed. However, the survey approach (online and based on the snowball effect) did not allow us to achieve this objective. A total of 310 respondents completed the questionnaire, representing $85.4 \%$ of the estimate.

The majority were men (219 or $70.6 \%$ ). Two age groups (21-30 years and 31-55 years) were registered, the most represented being 31-55 years, with 255 respondents representing $82.4 \%$.

The different marital status are represented, the most numerous being 128 or $41.2 \%$ married, followed by single persons (91 or $29.4 \%$ ).

For the level of education, we note that all respondents were educated. The vast majority (292 or $94.1 \%$ ) have a higher level of education. This data is probably due to the possession of an email address. This mode of communication is very often used by the population with a high level of education.

Contrary to the distribution of respondents in the sample, 274 or $88.2 \%$ of respondents were from Cocody and 36 or $11.8 \%$ from Bingerville (see Table 2).

Table 2. Socio-demographic characteristics of respondents.

\begin{tabular}{lll}
\hline Actual & Variables $(\mathbf{n}=\mathbf{3 1 0})$ & Pourcentage \\
\hline Gender & & \\
Man & 219 & 70.6 \\
Woman & 91 & 29.4 \\
Age & & \\
$15-20$ years & 0 & 0.0 \\
21-30 years & 55 & 17.6 \\
$31-55$ years & 255 & 82.4 \\
$56+$ & 0 & 0.0 \\
Marital status & & \\
Single & 91 & 29.4 \\
Concubine & 36 & 11.8 \\
Married & 128 & 41.2 \\
Widowed & 36 & 11.8 \\
No response & 18 & 5.9 \\
School level & & \\
None & 0 & 0.0 \\
Primary & 0 & 0.0 \\
Secondary & 18 & 5.9 \\
Higher & 292 & 94.1 \\
Residence & & 88.2 \\
Cocody & 274 & 11.8 \\
Bingerville & 36 &
\end{tabular}

Source: Notre enquête, Juillet-Aout 2020

\subsection{Strategies to Combat COVID 19}

\subsubsection{Control Measures}

\section{(i) Physical Barriers}

The physical measures published by the Ivorian authorities are:

1) the blockade of greater Abidjan, 
2) containment,

3) curfew,

4) a state of emergency,

5) the closure of the various borders,

6) travel limits for essential activities,

7) a ban on gatherings of more than 50 people,

8) social distance of at least $1 \mathrm{~m}$,

9) closures of venues, cults and restaurants.
As a result of the survey, the analysis of the results shows that the various measures were mentioned by the interviewees. However, the ban on gatherings of more than 50 people (219 people surveyed, or $20.0 \%$ ), confinement (182 or $16.7 \%)$, social separation of at least $1 \mathrm{~m} \mathrm{(164} \mathrm{or}$ $15.0 \%$ ) and the blockade of greater Abidjan (146 or 13.3\%) were the most cities (see table 3).

Table 3. Physical measures.

\begin{tabular}{lll}
\hline Actual & Variables & \% \\
\hline Closure of venues, cults and restaurants & 18 & 1.7 \\
Limit of travel to essential activities & 55 & 5.0 \\
State of emergency & 73 & 6.7 \\
Curfew & 109 & 10.0 \\
Closure of the various borders & 128 & 11.7 \\
Blockade of Greater Abidjan & 146 & 13.3 \\
Social distance & 164 & 15.0 \\
Containment & 182 & 16.7 \\
Prohibition of gatherings of more than 50 persons & 219 & 20.0 \\
Total & 1094 & 100.0 \\
\hline
\end{tabular}

Source: Our survey, July-August 2020

\section{(ii) Health Barriers}

The health measures published by the Ivorian authorities are:

1) regular hand washing,

2) mask wearing,

3) cough or sneeze in a disposable handkerchief or between the elbow,
4) contact caregivers in the event of symptoms,

5) avoid touching your face.

After the survey, the interviewees did list these measures. However, those related to the wearing of the mask (255 or $31.1 \%$ ) and regular hand washing (201 or $24.4 \%$ ) were the most cited (see Table 4).

Table 4. Health Barriers

\begin{tabular}{lll}
\hline Actual & Variables & \% \\
\hline Regular hand washing & 201 & 24.4 \\
Touch or sneeze in disposable handkerchief or between elbow & 182 & 22.2 \\
Mask port & 255 & 31.1 \\
Contact caregivers for symptoms & 164 & 20.0 \\
Avoid touching your face & 18 & 2.2 \\
Total & 821 & 100 \\
\hline
\end{tabular}

Source: Our survey, July-August 2020

\section{(iii) Dissemination of Measurements}

For the dissemination of these measures, all channels of communication have been mobilized. They range from traditional media (radio, TV, print) to ICT (internet, whatsapp, facebook, SMS, etc.). Changes in the various media programs were recorded. Thus, in the TV Journal of the Ivoirian Radio and TV 1 (RTI 1), the situation in Côte d'Ivoire and the press point were two spaces dedicated to the response of the covid 19, where is made the assessment of the measures, the spread and the management.

Furthermore, in the interest of proximity, ICTs have been mobilized. In fact, in the search for greater proximity of organizational actors to citizens, information via SMS (Short Message Service) signed by either a mobile phone operator or the government, or both, has been disseminated every day. Thus, all respondents were unanimous about receiving "signed government text messages" on the various mobile phone networks.

In addition to emergency numbers such as $101,125,143$, etc. have been put into service. For example, "in the event of coughing, fever, aches and/or breathing difficulties, you are asked to contact the following free numbers as a matter of urgency: 143, 125 or 101" advises MSHP.

Also, songs by several artists were produced to not only raise awareness but also combat fake news and disinformation. AH. Mahe [9] noted: "since the beginning of the pandemic, many artists have been mobilizing to contribute to the building of the fight against the Covid-19. Some, like Banksy, decide to use their reputation and their art to raise funds to help the carers, others decide to act upstream of the contamination, recalling the gestures barriers to be respected. [...] In Côte d'Ivoire, six artists decided to combine their talents to compose and interpret "Enemy of Health". In a six-minute clip, already seen 40,000 times in two days, Kajeem, Nash, the singers of the TNT group and the slammers Amee and Kapegik promote the gestures barriers to prevent the spread of Covid-19 and highlight the need for solidarity". 
3.2.2. Impact Des Stratégies de Lutte Dans la Production de la Stigmatisation Impact of Control Strategies in the Production of Stigma

\section{(i) Production of Stigma Due to COVID 19}

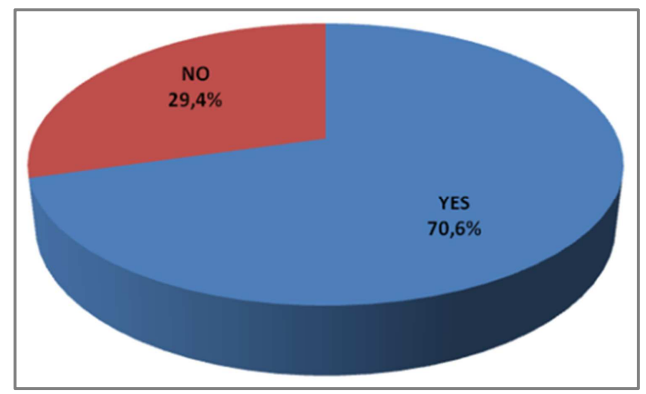

Source: Our survey, July-August 2020
An analysis of Figure 1 above shows that the majority of respondents (219 or $70.6 \%$ versus 91 or $29.4 \%$ ) noted that Covid 19 may have generated stigma. This stigma was manifested by the suspicion of feverish patients in hospitals or clinics (146 or $25.8 \%$ ), the suspicion of feverish patients going to pharmacy (73 or $12.9 \%$ ), social rejection (128 or $22.6 \%$ ), the labeling of individuals (91 or $16.1 \%$ ), geographical labeling (91 or 16.1\%) and Community withdrawal (36 or 6.5\%) (see figure 2 below).

As for those who thought otherwise, the advances are:

"Covid 19 did not create the same psychosis as HIV, because the population thinks that this disease is not serious, so it cannot generate psychosis" or "The symptoms described are similar to those of influenza and malaria, two diseases already common; although the beginnings were difficult for all." (Source: Our survey, July-August 2020)

Figure 1. Generating stigma due to covid-19.

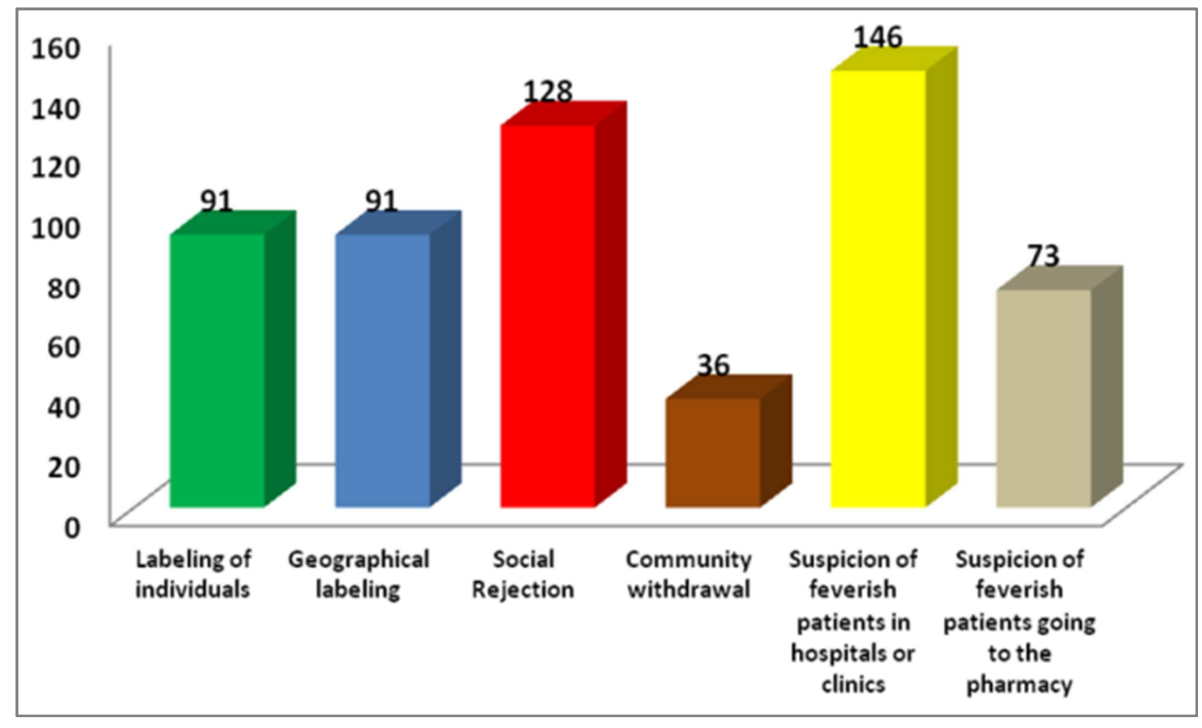

Source: Our survey, July-August 2020

Figure 2. Demonstration of stigma.

(ii) Production of Stigma Due to Measures to Combat COVID 19

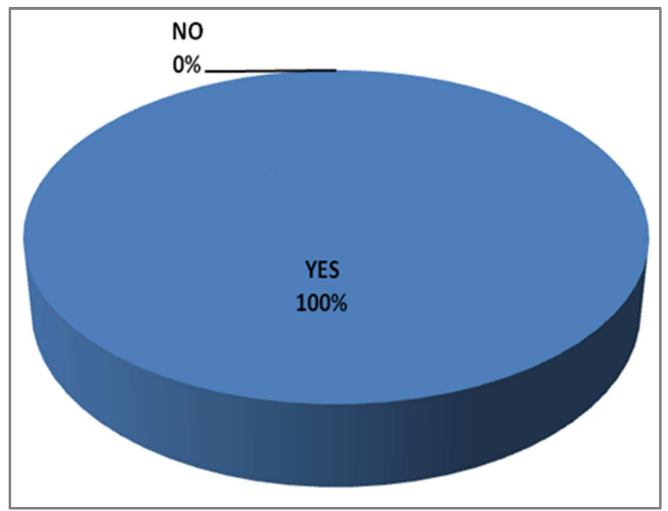

Source: Our survey, July-August 2020

Figure 3. Production of stigma due to measures to combat covid 19.
The respondents unanimously noted that the various measures taken by the Ivorian government to combat Covid 19 have been a source of stigmatization.

\section{(iii) Determination of Stigma}

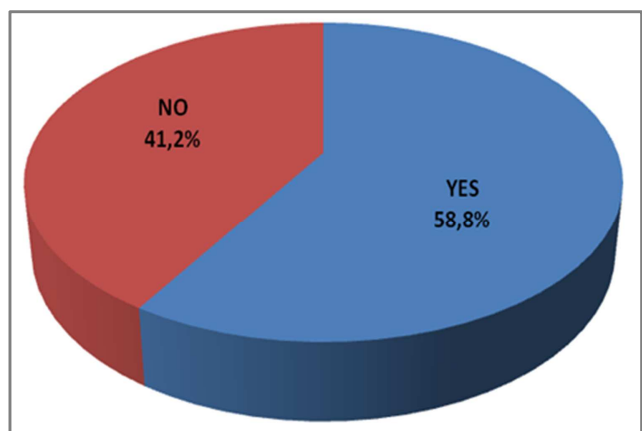

Source: Our survey, July-August 2020

Figure 4. Survey findings of stigmatization. 
In order to raise awareness of the actual existence of Covid 19, RTI 1 broadcast on Friday, April 17, 2020, the testimony of a healed patient. His testimony reveals two major facts: the existence of covid 19 and stigma. Thus, she revealed "I tested positive on the covid and immediately I was admitted to a treatment center for the covid 19 patients [...] Today, after two negative tests, I was declared cured of the coronavirus. So I would like to take this opportunity to say that this is a real disease and avoid stigmatizing people who may be infected around you. I experienced it bitterly. I felt like my world was falling apart knowing that the people I valued could turn their backs on me outright because I had been infected. It is a difficult situation, I can assure you. But today, by the grace of god we are before you and we will want to avoid stigma because stigma is much more painful than the disease itself. Stigma hurts a lot more; it kills a lot faster than the disease coronavirus. I would really like to invite you to give all your support to your loved ones who might suffer from this disease" (source, RTI1, Friday 17 April 2020) [11].

Based on this report, a question on the observation or finding of stigmatization in their environment was addressed to the respondents. The analysis of the results shows that 182 or $58.8 \%$ of the respondents made the same observation, compared to 128 or $41.2 \%$.

These data reveal that stigma is an observable fact in this period of covid-19.

\subsubsection{Link Between Strategies for Combating and Producing Stigmatization}

\section{(i) Contribution of the Speech "COVID 19 Is an Imported Disease"}

The first speeches of the health authorities, the National Security Council (NSC) and the government were to present Covid 19 as an "imported disease". Thus, in the response strategies against this disease, the Ivorian government has made the following hypotheses on the basis of the "current development of coronavirus disease (COVID-19)" in the response plan: (i) First low-risk hypothesis, (ii) Second highrisk hypothesis.

1. The low and immediate risk hypothesis is characterized by a slow spread of covid 19 marked by imported cases of covid 19 with transmission stopped by compliance by the population with governmental measures;

2. The high-risk hypothesis would be characterized by the rapid spread of covid 19 by the failure of the population to comply with governmental measures with the emergence of indigenous cases and an overflow of care services the public's non-compliance. With government measures, this step would be marked [2].

This characterization of covid 19 as an "imported disease", according to 219 or $70.6 \%$ against 91 or $29.4 \%$ of the respondents, could contribute to the stigmatization. Thus, it was heard in the communities that "the $\mathrm{kg}$ of the benguistes ${ }^{3}$ had become cheaper".

3 The name given to Western countries in the Nouchi language in Ivory Coast is Bengué. Thus, all who stay there are called Benguistes.

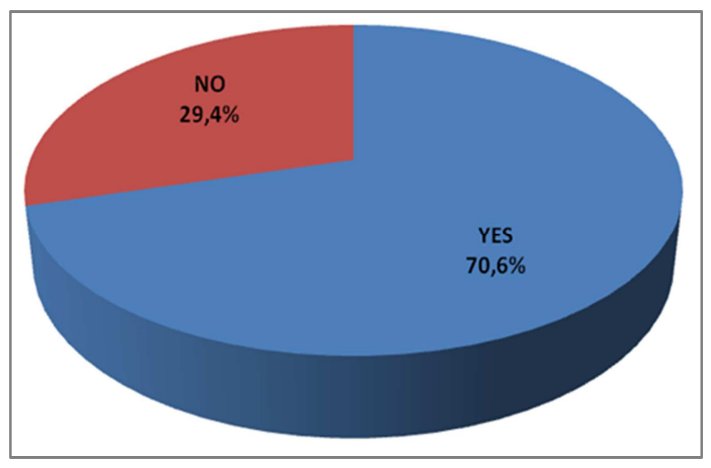

Source: Our survey, July-August 2020

Figure 5. Contribution of the discourse "covid 19 disease is an imported disease" in the production of stigma.

\section{(ii) Contribution of the Dissemination of Data (Number of Positives and Deaths) on Pathology}

Table 5. Contribution of data dissemination (number of positives and deaths) to the production of stigma.

\begin{tabular}{lllll}
\hline \multirow{2}{*}{ Responses } & National & \multicolumn{3}{c}{ International } \\
\cline { 2 - 5 } & Variables & $\mathbf{\%}$ & Variables & $\mathbf{\%}$ \\
\hline YES & 164 & 52.9 & 255 & 82.4 \\
NO & 146 & 47.1 & 55 & 17.6 \\
Total & 310 & 100.0 & 310 & 100.0 \\
\hline
\end{tabular}

Source: Our survey, July-August 2020

To support the seriousness of the global health situation, the dissemination of data (number of positive and death) on the disease was carried out by the various national and international media. This media campaign has attracted the attention of the various actors for a long time. It has evolved with the different epicenters of the pathology respectively in Asia, Europe, America and more or less in Africa.

The survey found that the majority of respondents noted that the dissemination of these data not only supported the health severity thesis, but also generated the stigmatization of populations living in higher-risk geographic areas. This reading was more important at the international level (255 or $82.4 \%$ ) than at the national level (164 or $52.9 \%$ ).

\section{(iii) Contribution of the Dissemination of Pathology Data by Health District}

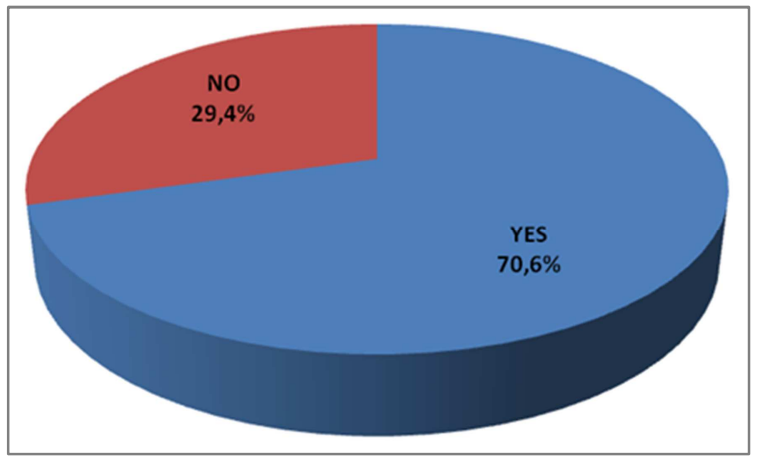

Source: Our survey, July-August 2020

Figure 6. Contribution of data dissemination by health district. 
One of the main lines of communication of the Ministry of Health was to disseminate data on pathology by health district. For example, the health district with the highest number of positive cases was Cocody-Bingerville, with $39 \%$ of confirmed cases [10]. The sharing of these data was probably to draw the attention of the population residing in the other health districts to the arrangements to be made to move in this district at risk. According to 219 respondents, $70.6 \%$ of the respondents, were able to contribute to the stigmatization of populations in districts at risk.

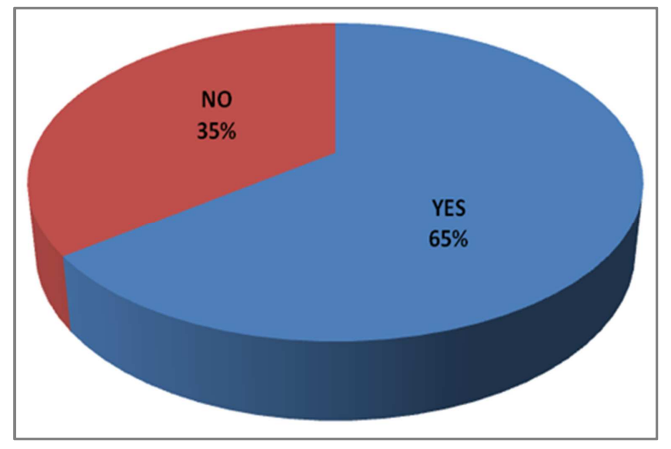

Source: Our survey, July-August 2020

Figure 7. Contribution of the blockade of Greater Abidjan to stigmatization.

\section{(iv) Contribution of the Blockade of Greater Abidjan}

The Autonomous District of Abidjan was the epicenter of Covid 19 with $95 \%$ of confirmed cases [10]. This situation has led the government to take the blockade of Greater Abidjan as a measure in order to better manage the risk of contraction and spread of the disease. Its characteristic was the prohibition to enter and leave this geographical area. The movements of the populations in both directions (entry and exit) were subject to a pass issued by the administrative authorities (Prefects, Sub prefects) and police. According to 201 respondents, $65 \%$ of respondents, this action has led to the stigmatization of the different populations living in this geographical area.

\section{(v) Contribution of Rapid Response Teams (RRTs)}

Table 6. Contribution of RRTs' outfits and response approaches.

\begin{tabular}{lllll}
\hline & Outfits & \multicolumn{3}{c}{ Interventions } \\
\cline { 2 - 5 } & Variables & $\mathbf{\%}$ & Variables & $\mathbf{\%}$ \\
\hline YES & 146 & 47.1 & 164 & 52.9 \\
NO & 164 & 52.9 & 146 & 47.1 \\
Total & 310 & 100.0 & 310 & 100.0 \\
\hline
\end{tabular}

Source: Our survey, July-August 2020

In the community care of Covid 19, the government, through the Ministry of Health and Public Hygiene, set up in each commune medical teams called Rapid Intervention Teams (EIR) whose coordination was based at the National Institute of Public Hygiene (INHP). The EIRs are equipped

4 In addition to the 13 municipalities of the autonomous district of Abidjan, the perimeter of Greater Abidjan includes the towns of Dabou, Assinie, Azaguié, Alpe, Bassam, Bonoua, Brofodoumé, Oghwlapo and Jacqueville. with appropriate clothing (see figure 8), rolling stock stamped "Rapid Response Teams (RRTs)" with a flashlight causing noisy and non-discreet passages that "leave no one indifferent during the passages". Instead, they arouse "curiosity, fear and even indexation of the families visited", say respondents.

More than half of the respondents (164 out of 323 , or $52.9 \%$ compared to 146 or $47.1 \%$ ) noted that the way in which the RRTs were used contributed to stigmatization. On an equal basis, however, the respondents indicated that the conduct of RRTs could not contribute to stigmatization.

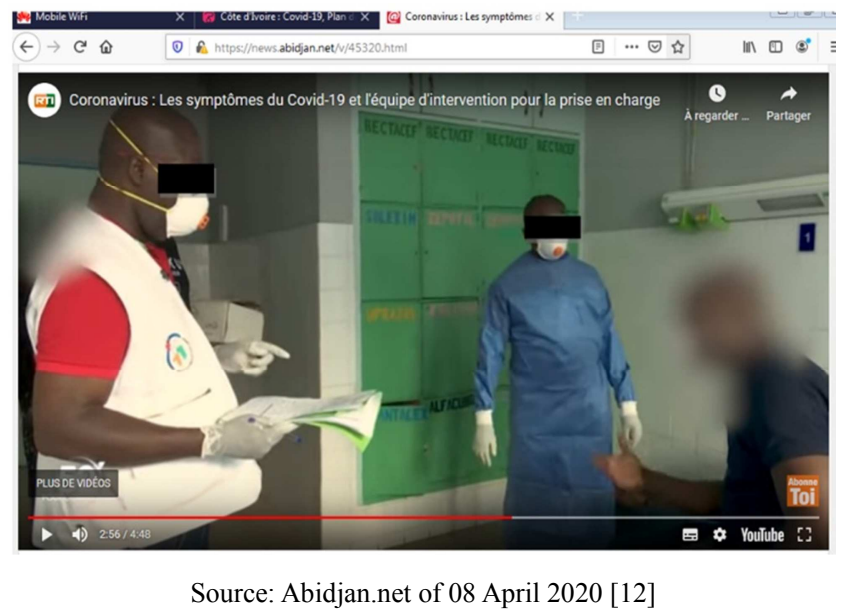

Figure 8: Members of a Rapid Response Team (RRT) when taking over covid 19.

\section{Discussion}

\subsection{Control Strategies Supported by Extensive Communication Campaigns}

According to the WHO [3], "in a short period of time, the localized outbreak of COVID-19 has evolved into a global pandemic with three fundamental characteristics [namely] the speed and extent of its explosive spread around the world saturating even the most resilient health systems, severity $(20 \%$ of infected people develop a serious or critical form of disease, with a gross lethality rate currently above 3\%, which increases in the elderly and those with certain underlying pathologies) and societal and economic disruption".

In response to the pandemic described as a 'health tsunami' by France 24 [13], response plans have been adopted at both national and international level. On the one hand, these measures have been described as physical barriers (containment, closure of the various borders, limitation of movements to essential activities, social separation of at least $1 \mathrm{~m}$, prohibition of gatherings of more than 50 people, closure of venues, cults and restaurants, curfew, state of emergency, blockade of homes (example of the greater Abidjan). On the other hand, the sanitary measures were regular hand washing, wearing masks, coughing or sneezing in a disposable handkerchief or between the elbow, contacting carers in case of symptoms and avoiding touching the face. 
The application of these various measures has, according to the WHO [3], helped to curb the spread. Indeed, she informed that "by putting societies and economies at a standstill, we have reduced the capacity of the virus to spread in our communities. These defensive measures have reduced some of the short-term impacts of the virus and bought time to translate what we learned about the virus into solutions that will allow us to return to a more normal lifestyle: a new normal."

As is the case with Covid-19, in a health crisis, the information challenge is important. All the different channels, means and techniques of communication were mobilized. Indeed, since its appearance, Covid-19 has occupied an important place in the public space and has been the subject of strong media coverage, particularly in the classical media (radio, television, print media...).

In addition, as A. Merah [14] pointed out, "the introduction of information and communication technologies (ICTS) in the field of health (telemedicine, networking, scientific dissemination and above all general, specialized and preventive information) has made it one of the most computerized and most present domains on the Internet". Since then, health issues have not only been addressed in the traditional media public space. They find themselves increasingly in the new virtual space to give birth to a new niche that is the medical Net. H. Romeyer [15] believes that "the deployment of information and communication technologies (ICTS) has caused a shift from medical information to health information". Thus, "Covid-19 hashtags followed by the initials of each country were created on Twitter. The creation of Facebook pages and groups as well. A lot of information around Covid-19 also circulates through Whats App groups [16]".

T. Atenga [17, 18] stressed that in the search for greater proximity of organizational actors to citizens and their information through techno-informational and communication devices such as Short Message Service (SMS) signed by a mobile phone operator, the Ministry of Public Health or even the two that Cameroonians receive each week.

The fight against Covid-19 was also the occasion for the visibility of African local intelligences. Initiatives to monitor the pandemic by drones such as the GML project and Co drone response Covid in Cameroon, and the dissemination of awareness messages through information and communication technologies have multiplied. In the same vein, efforts to scale up technology applications and digital platforms have been widespread in most African countries. Thus, DiagnoseMe in Burkina Faso allows an epidemiological follow-up of Covid-19 in real time; REMA Medical Technology in Benin promotes exchanges between doctors and is intended to be a platform for pooling efforts; SunuCity in Senegal intends to solve the problem of saturation of the green number of the Ministry of Health; SOS-Covid in Cameroon has the special feature of rapidly detecting symptoms of Covi-19; Alafia wincovid-19 in Gabon has for specificity the tracking of cases at risk, etc.

\subsection{Stigma, a Legitimate Social Reaction}

In the case of stigma related to infectious diseases, stigmatization, blaming others, and discrimination are exacerbated by fear of illness. It is not always done consciously and might serve several means. In the face of an unfamiliar or intolerable adverse situation (here, lack of knowledge about the source of infection and protective measures) or an unknown hazard (insufficient scientific understanding about the infection source), stigmatization can temporarily bring feelings of security even if it is not a real or a permanent one. This is done by distancing from the source of the threat (here infected people), through dividing people into "them" and "us." The underlying thought is: we are not them, we do not possess the same risk factors, so we are not in danger [19].

Indeed, like all emerging diseases, the novelty of Covid 19 and the fear of the unknown have led to the stigmatization of patients, their surroundings and their living area. One of the organizations accustomed to this behavioral shift, UNESCO [20], has attracted the attention of the international community. UNESCO pointed out that "the current epidemic of covid 19 has led to social stigmatization and discriminatory behavior. [...] A lack of understanding or insufficient access to information can cause fear or panic within communities, leading to irrational assumptions and the need to blame others. The confusion, anxiety and fear among the population are hardly surprising. It is tragic that these factors - confusion, anxiety and fear - fuel harmful stereotypes and racism. We hear more and more about Asians or people of Asian origin, tourists, students and long-term residents who are being abused and discriminated against because of misconceptions that they may be a source of the new coronavirus (COVID-19)."

This production of stigma was noted and reported by Safiatou Ouédraogo, coordinator of the rapid response team at the Ouagadougou Urban Medical Center, who said "he said that since we went to his house to take samples, even before the results of the tests were known, nobody came to visit them anymore. Everybody looked at them strangely. It was really difficult for them"[21].

This fear of stigmatization has caused the population to "hesitate to get tested, avoid those in charge of finding contacts or be suspicious of what neighbors will say: the pandemic of covid 19 has triggered various reactions among some Ouagadougou residents that have made the response more difficult. When the National Rapid Response Team tried to get in touch with a man who had been in contact with a patient being treated at a hospital in Ouagadougou, he first refused to take the calls, then promised to show up for a test and finally, asked that the team only come home at night [...] to some families, each visit requires new negotiations to allow the intervention team to keeping track of contacts or disinfecting the premises [because] we found that the reaction of neighbors to the family every time we came to collect samples created new injuries."

In response, Safiatou Ouédraogo [21] explains, "this can 
compromise social cohesion and push the population to hide the disease to avoid discrimination. It can also deter people from seeking immediate treatment or taking preventive measures. [...] Because of the stigma, people prefer that the rapid response team does not show up at home."

This perception of covid 19 goes beyond positive people. It also affects the medical profession. This is the observation made by Dr. Brice Bicaba, the National Coordinator of the response to covid 19 of Burkina Faso. He observed that "not only are patients stigmatized, but also health workers, especially those in the treatment centers of Covid 19, are discriminated against by their communities who fear that their work exposes them to an increased risk of contracting the virus" [21].

\subsection{Stigma, Response Plans Result}

The various authors reveal that there is a link between the response plans and the production of the stigma, that of the resultant or cause-effect.

Indeed, Saeed and al [22] identified the factors that cause stigma can be divided into three categories: predisposing (facilitators), precipitating (triggers), and perpetuating factors Factors such as social structures and policies can increase stigma both as a predisposing and perpetuating factor, and require long-term planning. Factors such as insufficient information or contradictory messaging are precipitating factors and can be managed with immediate strategies that will be discussed here.

Patients' isolation and quarantine are effective measures, but they can increase stigma and severely impact on mental health and the economy. Isolation, loss of jobs, and financial burden, among other factors, can increase the risk of depression, especially in at-risk populations [22-25].

In public health, persistently opposing the "general public" to "at-risk group" carries out the message of "in-group" vs. "out-group" that contributes to stigma formation [26]. Thus, infectious disease pandemics are associated with social consequences and stigma that are noticeably similar in various health conditions, health systems, and cultures. Stigma impacts health-related outcomes, not only as a barrier to receiving the timely diagnosis and appropriate treatment but also as an important variable that increases mental health issues such as anxiety and depression. The COVID-19 outbreak has been associated with stigma too. Nowadays, many people suffering from COVID-19 are challenged doubly, both by the disease and by the stigma associated with it [22].

T. Ramaci [27] noted, on the basis a self-administered multiple-choice questionnaire developed by See and al. [28] about attitudes of discrimination, acceptance, and fear towards HCWs exposed to COVID-19, that stigma has a high impact on workers' outcomes.

The same is true of other pandemics, as noted above by Hargreaves and al, Pfefferbaum and al. they wrote "From the 19th century's smallpox to the 21st century's COVID-19, epidemics and pandemics have always been associated with stigma and severe social consequences [29-30].

\section{Conclusion}

Like all emerging diseases, the control of Covid 19 has been a succession of approaches, policies, health responses and partly different social responses. The analysis of the data indicates that the fight against Covid 19 has mobilized a plethora of strategies supported by an extensive media campaign. Their summation led to the fact that "the whole planet has almost stopped living". The different strategies adopted have fanned and reinforced the fear of disease and death. As a result, they have led to attitudes that reject and stigmatize positive people and their loved ones.

That is to say, stigma is prevalent in strategies to combat covid 19. Therefore, we consider that the different strategies for responding to emerging diseases contribute in large part to the production of this social reaction, which is a legitimate response based on the survival instinct buried in each individual.

\section{References}

[1] Nicolle C. (1939). The Fate of Infectious Diseases. Paris: The Presses universitaires de France, 3rd edition, 303p.

[2] Minister of Budget and State Portfolio. (March 2020). Ivory Coast: Covid-19, Response Plan for Acute Respiratory Infections in Coronavirus. Abidjan, 12p.

[3] WHO. (14 April 2020). Update of the covid-19 strategy, Geneva, 20p.

[4] Johns Hopkins University and Medicine. (2020). Covid-19 Global map, [online], available at https://coronavirus.jhu.edu/map.html.

[5] UNAIDS. (19 March 2020). HIV and covid-19: information for people living with HIV. Geneva, $4 p$.

[6] National Institute of Statistics (INS). (2015). General Census of Population and Habitat 2014. Abidjan, 49p.

[7] Rongere, P. (1970). Social Science Method Memo. Paris, Dalloz, 108p.

[8] Masse, R. (2003). Ethics and Public Health, Issues, Values and Normativity, Ste-Foy: Presses de l'Université Laval, with the collaboration of Jocelyne St-Arnaud, 430p.

[9] Mahe A.-H. (May 15, 2020). Six Ivorian artists join forces to fight against Covid-19 in song, ICRC, [online], available at https://blogs.icrc.org/hdtse/2020/05/15/six-artistes-ivoiriens-sassocient-pour-lutter-contre-le-covid-19-en-chanson/, accessed August 10, 2020.

[10] John Hopkins University/Africa CDC/ Ministry of Health and Public Hygiene Ivory Coast. (May 2020). General Covid 19 to May 1, 2020, 1p. [online], available at http://infocovid19.gouv.ci/assets/fichiers/Bilan_COVID19.pdf.

[11] RTI1. (Friday 17 April 2020). Coronavirus: A healed patient in Ivory Coast testifies and calls not to stigmatize, Abidjan, [online], available at www.rti.ci, info , company, coronavirus-une-patient-guerie.

[12] Abidjan.net. (08 April 2020). Coronavirus: Symptoms of Covid-19 and Rapid Response Team, Abidjan, [online], Available at https://news.abidjan.net/v/45320.html. 
[13] France 24. (20 October 2020). Paris live: JT 09: 30 pm of 20 October 2020, Paris.

[14] MERAH A. (2014). "Professional use of information on the Internet. Case of health journalists". French Journal For Media Research, 1/2014, ISSN 2264-4733.

[15] Romeyer, H. (2008). "ICT and health: between medical information and health information". Tic \& society, 2 (1), 2644.

[16] Giardinelli, A. (27 July 2020). Call for papers: Media, Social Media Networks and Covid-19 in Africa". Calenda, Université Grenoble Alpes, France, 8 p.

[17] Atenga T. (2015). Journals, Journalists and Ebola in Cameroon. A study of discursive registers, communication at the Ebola Epidemic Symposium in West Africa. Comparative ethno-social approaches, Dakar, 19-21 May 2015.

[18] Atenga T. (2020). "ICT issues in public health awareness and prevention in Cameroon".36-156. Atenga, T., Madiba, G. ( $\mathrm{s} /$ coord.). Development issues in the information and communication sciences. Mixtures offered in Misse Misse, Louvain-la-Neuve, editions Academia, 448p.

[19] Gilmore N, Somerville MA. (1994). "Stigmatization, scapegoating and discrimination in sexually transmitted diseases: overcoming 'them' and 'us'". Soc Sci Med. 39: 1339-58. doi: 10.1016/0277-9536(94)90365-4.

[20] UNESCO. (25 May 2020). Discrimination and Stigma in relation to Code 19: a global phenomenon? [online], available at https://fr.unesco.org/news/discrimination-stigmatisationliees-au-covid-19-phenomene-mondial, accessed august 10, 2020 .

[21] WHO Burkina Faso. (23 July 2020). Combating fear and stigma related to COVID-19, [online], available at https://www.afro.who.int/fr/news/combattre-la-peur-et-lastigmatisation-liees-la-covid-19, accessed 15 August 2020.

[22] Saeed F, Mihan R, Mousavi SZ, Reniers RL, Bateni FS,
Alikhani R and Mousavi SB. (2020). "A Narrative Review of Stigma Related to Infectious Disease Outbreaks: What Can Be Learned in the Face of the Covid-19 Pandemic?". Front. Psychiatry, 11: 565919. doi: 10.3389/fpsyt.2020.565919.

[23] Brooks SK, Webster RK, Smith LE, Woodland L, Wessely S, Greenberg N, and al. (2020). "The psychological impact of quarantine and how to reduce it: rapid review of the evidence". Lancet, 395: 912-20. doi: 10.1016/S0140-6736(20)30460-8.

[24] Cava MA, Fay KE, Beanlands HJ, McCay EA, Wignall R. (2005). "The experience of quarantine for individuals affected by SARS in Toronto". Public Health Nurs. 22: 398-406. doi: 10.1111/j.0737-1209.2005.220504.x.

[25] Mousavi SB. (2020). "Coronavirus disease 2019 pandemic: do not forget patients with severe mental illness". Int J Soc Psychiatry. doi: 10.1177/0020764020939982.

[26] Mawar N, Sahay S, Pandit A, Mahajan U. (2005). "The third phase of HIV pandemic: social consequences of HIV/AIDS stigma \& discrimination \& future needs". Indian J Med Res, 122: 471 .

[27] Ramaci T, Barattucci M, Ledda C, Rapisarda V. (2020). "Social stigma during COVID-19 and its impact on HCWs outcomes". Sustainability, 12: 3834. doi: 10.3390/su12093834.

[28] See, L. C.; Shen, Y. M.; Chen, C. L.; Huang, T. M.; Huang, Y. H.; Huang, H. C.; Lin, S. R. (2011). "Professional attitude of health care workers toward serving HIV/AIDS patients and drug users: Questionnaire design and evaluation of reliability and validity". AIDS Care, 23: 1448-1455. [CrossRef].

[29] Hargreaves J., Davey C., Auerbach J., Blanchard J., Bond V., Bonell C., and al. (2020). "Three lessons for the COVID-19 response from pandemic HIV". Lancet HIV, 7:e309-11. doi: 10.1016/S2352-3018(20)30110-7.

[30] Pfefferbaum B, North CS. (2020). "Mental health and the Covid-19 pandemic". New Engl J Med, 383: 510-2. doi: 10.1056/NEJMp2008017. 